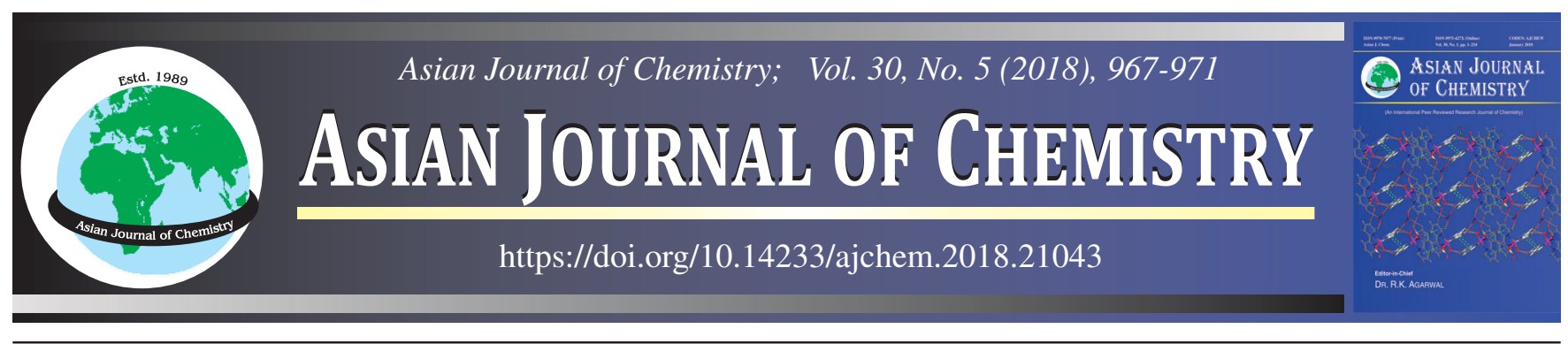

\title{
Effect of Bath Temperature on Magnetic and Structural Properties of Electrodeposited NiFeCr Nano Crystalline Thin Films
}

\author{
M. KANAKARAJ ${ }^{*}$ and H.B. RAMALINGAM
}

Department of Physics, Government Arts College, Udumalpet-642 126, India

*Corresponding author: E-mail: kanagarajbu@gmail.com

Received: 14 September 2017;

Accepted: 28 February 2018;

Published online: 29 March 2018;

AJC-18821

Soft magnetic thin films of $\mathrm{NiFeCr}$ were prepared using electrodeposition in various bath temperature. $\mathrm{NiFeCr}$ deposited films are textured with FCC phase preferred orientation. Experimentally observed soft magnetic property of thin films for different temperature was compared.The addition of chromium can enhance magnetic and mechanical properties of $\mathrm{NiFe}$ thin films. Electrodeposited $\mathrm{NiFeCr}$ films were prepared at different temperature $\left(30,50,70\right.$ and $\left.90{ }^{\circ} \mathrm{C}\right)$ and they were subjected to morphological, structural, magnetic and mechanical characterization analysis. Nickel content was maximum as $51.36 \mathrm{wt} \%$ at $90{ }^{\circ} \mathrm{C}$. The chromium content increased when electrolytic bath temperature was increased. $\mathrm{NiFeCr}$ films were bright and uniformly coated on the surface. Also the deposits of $\mathrm{NiFeCr}$ films were in nano scale and the average crystalline size was around $30 \mathrm{~nm}$. Thin films prepared at high temperature exhibited a high saturation magnetization and low coercivity. The micro hardness of $\mathrm{NiFeCr}$ was $272 \mathrm{VHN}$ at $90{ }^{\circ} \mathrm{C}$.

Keywords: Electrodeposition, Electrolytic bath, Crystalline size, VSM, Ni-Fe, X-ray diffraction, VHN, SEM.

\section{INTRODUCTION}

Soft magnetic nanocomposites are interesting materials because of their use in high frequency device application in variety of devices including on-chip micro-inductor, read write heads, magnetic sensors and spin valves $[1,2]$. NiFe thin films have been extensively used in practical device application [3-5]. NiFe alloy films with a composition of $\mathrm{Ni}_{82} \mathrm{Fe}_{18}$ is well known as a soft magnetic material and called permalloy [6,7]. $\mathrm{NiFe}$ films have relatively low resistivity, therefore gives rise to eddy current loss when used in microwave practical applications. Soft magnetic character of thin films are associated to crystalline nature and grain size of films [8-10]. Moreover, decrease in grain and interface role plays important role to enhance soft magnetic properties. The films should have low coercive field $\left(\mathrm{H}_{\mathrm{c}}\right)$, high magnetization, easily achievable and controllable anisotropy with small field, high resistivity and good thermal stability in reasonable temperature range [11-13]. Electrodeposition is an electrochemical process and an old method which applied for surface structure modification. Electrodeposition method is widely used in MEMS, NEMS, communication, optical and sensors industries [14-16]. $\mathrm{NiFeCr}$, $\mathrm{NiFeW}$ and $\mathrm{NiW}$ are most commonly used magnetic thin film materials in MEMS and NEMS.The electroplating of $\mathrm{NiFeCr}$ thin film is used to obtain enhanced soft magnetic characters, special optical properties and improved corrosion resistance $[7,17,18]$.

\section{EXPERIMENTAL}

The electroplated $\mathrm{NiFeCr}$ alloy films were prepared different temperature $30,50,70$ and $90{ }^{\circ} \mathrm{C}$. The time duration of deposition process was $15 \mathrm{~min}$. In this investigation, copper and stainless steel substrates acted as cathode and anode respectively with $1.5 \mathrm{~cm} \times 7.5 \mathrm{~cm}$. dimension [19]. The $\mathrm{NiFeCr}$ thin films were prepared from electrolytic solution which contain ferrous sulphate $(10 \mathrm{~g} / \mathrm{L})$, nickel sulphate $(30 \mathrm{~g} / \mathrm{L})$, chromium sulphate (15 g/L), ammonium sulphate (40 g/L), boric acid $(10 \mathrm{~g} / \mathrm{L})$ and saccharin $(10 \mathrm{~g} / \mathrm{L})$. The $\mathrm{pH}$ value of electrolytic solution was fixed as 6.0 by mixing ammonia solution and electroplating process was carried out with current density $3 \mathrm{~mA} / \mathrm{cm}^{2}$. The copper cathode was carefully removed from the bath after $15 \mathrm{~min}$ and dried for few minutes $[7,19,20]$. The surface nature of $\mathrm{NiFeCr}$ films was characterized by scanning electron microscope. The elemental content of deposits of films was examined by Energy-dispersive X-ray spectroscopy and crystal structure of deposits was analyzed by X-ray diffraction study. The micro hardness of films was measured by Vickers Hardness Test. The important magnetic properties of deposits are saturation magnetization and coercivity. Analysis 
of thin films with Vibrating Sample Magnetometer gives magnetic properties.

\section{RESULTS AND DISCUSSION}

Composition of NiFeCr films: Energy-dispersive X-ray analyzer (EDAX) gives elemental composition of deposits. Table-1 shows weight percentage of $\mathrm{Fe}, \mathrm{Ni}$ and $\mathrm{Cr}$ at different electrolytic bath temperature by EDAX analysis. The films prepared at $90^{\circ} \mathrm{C}$ have high content of chromium. The highest ferrous content of $26.27 \mathrm{wt} \%$ was found at electrolytic temperature of $30{ }^{\circ} \mathrm{C}$. While electrolytic temperature increases, the content of nickel and chromium also increase. The higher nickel content of $51.36 \mathrm{wt} \%$ was found at $90{ }^{\circ} \mathrm{C}$.

\begin{tabular}{cccc}
\multicolumn{4}{c}{ TABLE-1 } \\
\multicolumn{4}{c}{ EDAX ANALYSIS OF THIN FILMS } \\
\hline Temperature $\left({ }^{\circ} \mathrm{C}\right)$ & $\mathrm{Fe}(\mathrm{wt} \%)$ & $\mathrm{Ni}(\mathrm{wt} \%)$ & $\mathrm{Cr}(\mathrm{wt} \%)$ \\
\hline 30 & 26.27 & 41.11 & 32.62 \\
50 & 19.23 & 46.16 & 34.61 \\
70 & 13.62 & 49.05 & 37.33 \\
90 & 10.12 & 51.36 & 38.52 \\
\hline
\end{tabular}

Morphological study of NiFeCr films: The surface structure of $\mathrm{NiFeCr}$ thin films at temperature $30,50,70$ and $90{ }^{\circ} \mathrm{C}$ were analyzed by scanning electron microscope (SEM) images and shown in Fig. 1. The thin films are bright and uniformly coated on the surface. They are crack free by appearance.
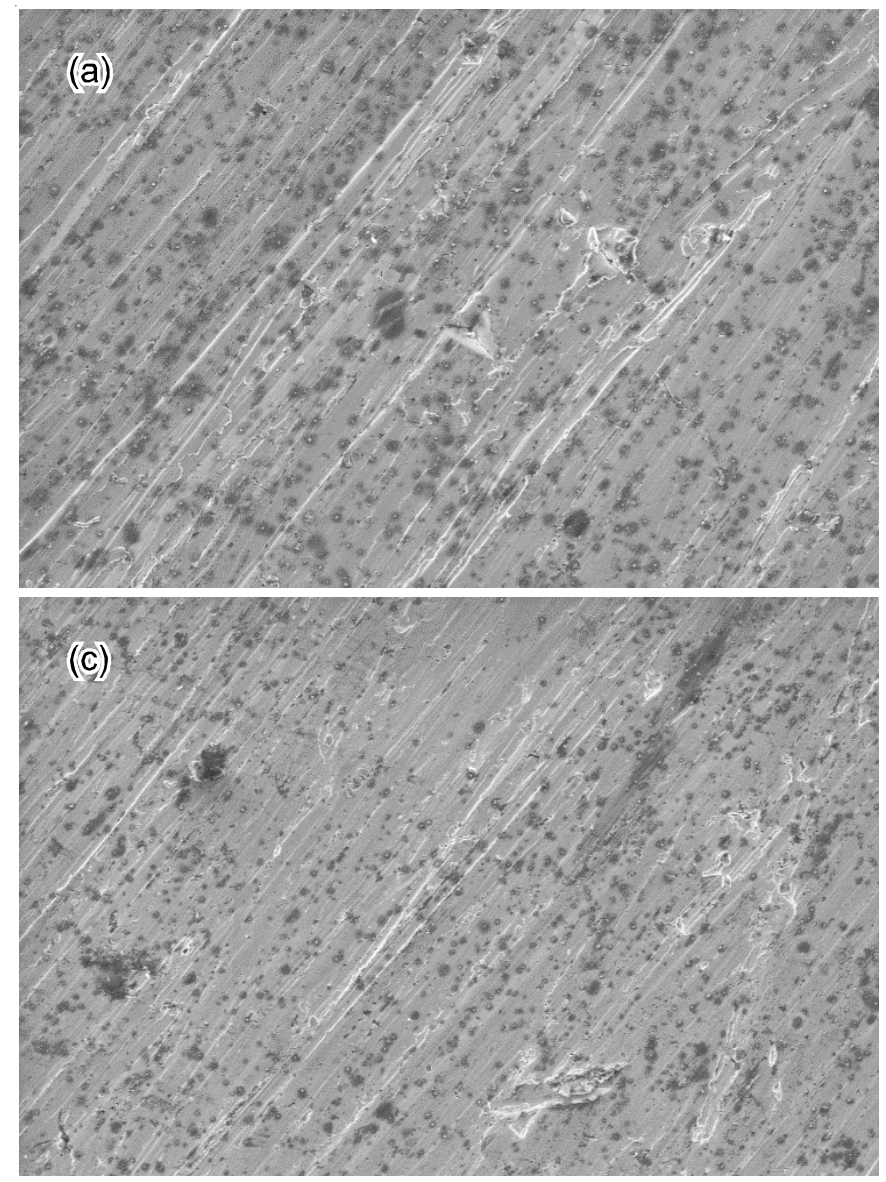

Structural analysis of NiFeCr films: Crystal structure of $\mathrm{NiFeCr}$ alloy films was analyzed by powder X-ray diffraction (XRD). Fig. 2 shows diffraction patterns of $\mathrm{NiFeCr}$ films prepared with different temperature. The occurrence of sharp peaks in X-ray diffraction pattern exhibit crystalline nature of deposits. The XRD patterns of all samples deposited at 30, 50,70 and $90{ }^{\circ} \mathrm{C}$ are being indicative of the (111), (200) and (220). Also XRD result reveal the existence of FCC type crystal. The particle sizes of $\mathrm{NiFeCr}$ deposits are $36.73,30.89$, 26.17 and $24.42 \mathrm{~nm}$ for the bath temperature 30, 50, 70 and $90{ }^{\circ} \mathrm{C}$, respectively. So it is concluded that crystal size of thin film deposits decreases by increasing electrolytic temperature. Also deposits of thin films revealed nanoscale and average crystalline size is around $30 \mathrm{~nm}$. When bath temperature increases, strain value increases from $0.986 \times 10^{-3}$ to $1.48 \times$ $10^{-3}$ dislocation density increases from $7.41 \times 10^{14} / \mathrm{m}^{2}$ to 16.77 $\times 10^{14} / \mathrm{m}^{2}$.

The crystal size, strain value and dislocation density of $\mathrm{NiFeCr}$ alloy films are shown in Table-2. The crystalline size of deposits decreases due to onset orientation of crystals while bath temperature increases. Fig. 3 shows that the crystal size reduces with increasing bath temperature.

Mechanical properties of NiFeCr films: Micro hardness measurement of deposits was done by Vickers hardness tester. The hardness values of thin films prepared for temperature $30,50,70$ and $90^{\circ} \mathrm{C}$ are $140,176,214,272$ VHN respectively. So hardness test shows that the micro hardness increases by increasing electrolytic bath temperature due to lower stress
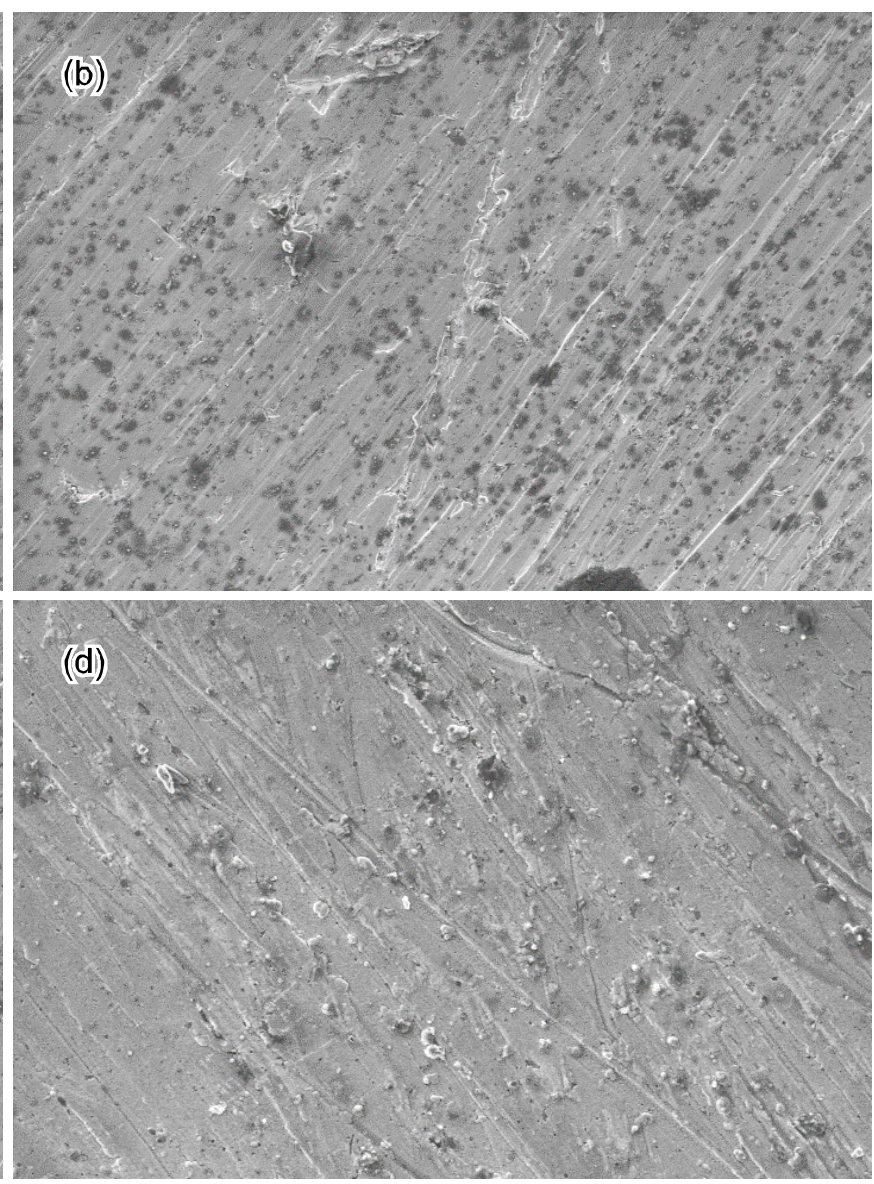

Fig. 1. NiFeCr films-SEM images at (a) $30{ }^{\circ} \mathrm{C}$ (b) $50{ }^{\circ} \mathrm{C}$ (c) $70{ }^{\circ} \mathrm{C}$ (d) $90{ }^{\circ} \mathrm{C}$ 

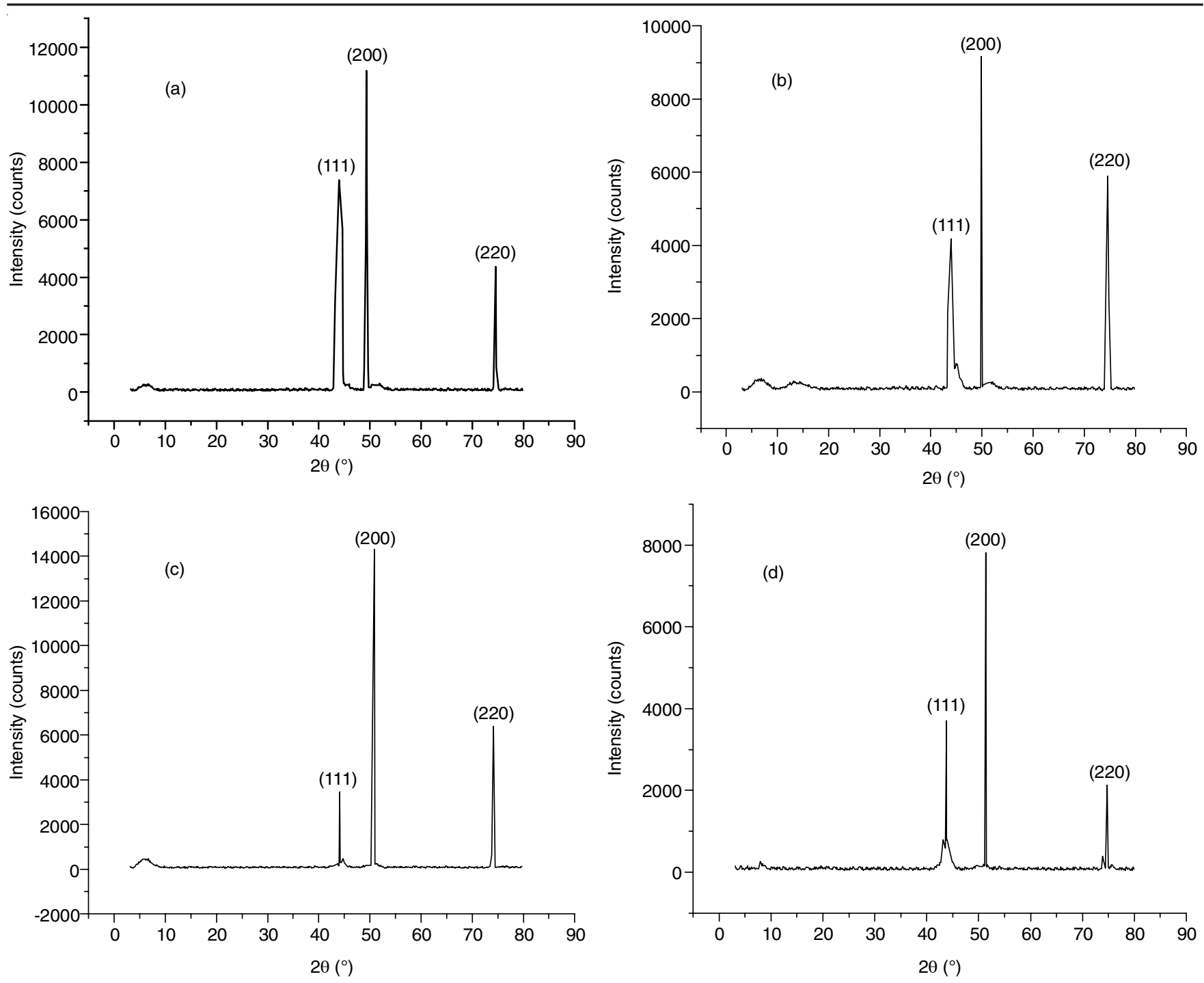

Fig. 2. NiFeCr films-XRD patterns at (a) $30{ }^{\circ} \mathrm{C}$ (b) $50{ }^{\circ} \mathrm{C}$ (c) $70{ }^{\circ} \mathrm{C}$ (d) $90{ }^{\circ} \mathrm{C}$

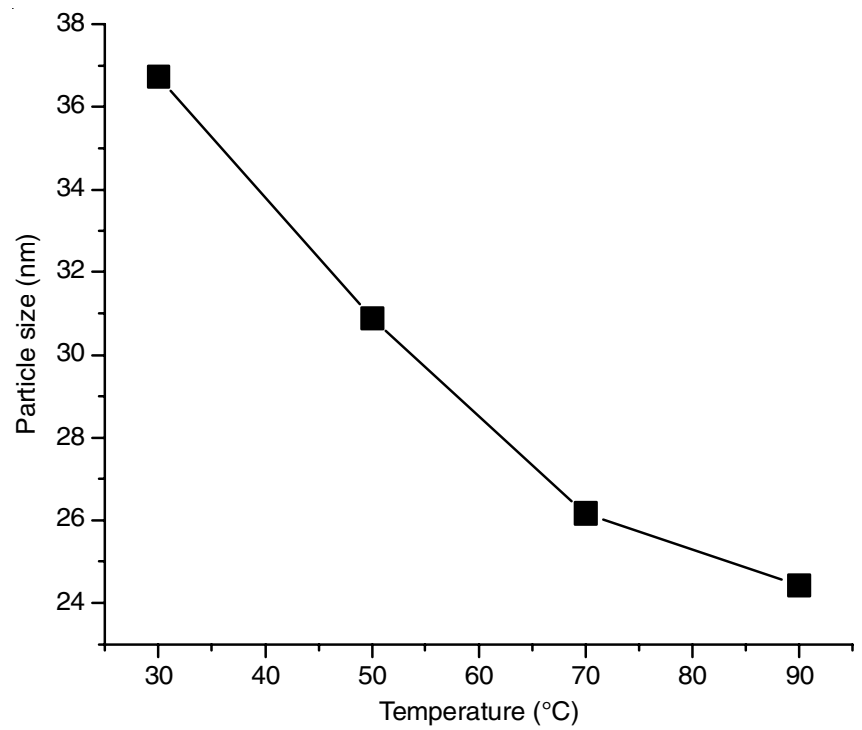

Fig. 3. Variation of crystal size with different electrolytic bath temperature

associated with thin films. Fig. 4 shows the variation of hardness with increasing bath temperature.

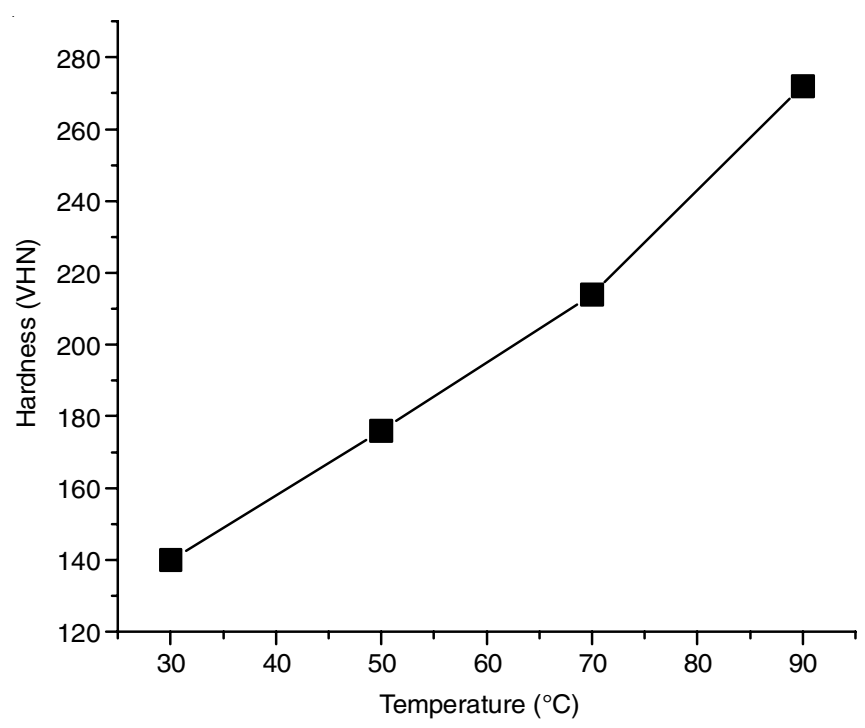

Fig. 4. Variation of micro hardness with different electrolytic bath temperature

Magnetic properties of $\mathrm{NiFeCr}$ films: The important magnetic characters coercivity, saturation magnetization, retentivity and squareness of $\mathrm{NiFeCr}$ alloy films were obtained 


\begin{tabular}{cccccc}
\hline \multicolumn{7}{c}{ TABLE-2 } \\
\multicolumn{7}{c}{ STRUCTURAL CHARACTERISTICS OF NiFeCr ALLOY THIN FILMS } \\
\hline $\begin{array}{c}\text { Bath temperature } \\
\left({ }^{\circ} \text { C) }\right.\end{array}$ & $2 \theta\left({ }^{\circ}\right)$ & $\mathrm{d}(\AA)$ & $\begin{array}{c}\text { Particle size }(\mathrm{D}) \\
(\mathrm{nm})\end{array}$ & Strain $\left(10^{-3}\right)$ & $\begin{array}{c}\text { Dislocation } \\
\text { density }\left(10^{14} / \mathrm{m}^{2}\right)\end{array}$ \\
\hline 30 & 49.27 & 1.894 & 36.73 & 0.986 & 07.41 \\
50 & 49.83 & 1.915 & 30.89 & 1.172 & 1.383 \\
70 & 50.93 & 1.713 & 26.17 & 1.48 & 14.6 \\
90 & 51.38 & 1.961 & 24.42 & & 16.77 \\
\hline
\end{tabular}

by VSM and are given in Table-3. The hysteresis curves for thin film $\mathrm{NiFeCr}$ with various temperature are shown in Fig. 5. The elemental composition of deposits, applied potential, additive materials, temperature and electrolytic bath are the deciding factors of thin film magnetic properties.

When electrolytic temperature is changed as $30,50,70$ and $90{ }^{\circ} \mathrm{C}$, the magnetization increases from $93.72 \times 10^{-3}$ to
$222.15 \times 10^{-3} \mathrm{emu} / \mathrm{cm}^{2}$. Also when temperature is increased from 30 to $90{ }^{\circ} \mathrm{C}$, the coercivity decreases from $364 \mathrm{G}$ to 132 G. From result of vibrating sample magnetometer, it is concluded that the films obtained at higher temperature reveals high value of magnetization and low value of coercivity. The enhanced value of saturation magnetization and reduced value coercivity promote magnetic properties of alloy coating.

\begin{tabular}{|c|c|c|c|c|}
\hline \multicolumn{5}{|c|}{$\begin{array}{c}\text { TABLE-3 } \\
\text { MAGNETIC PROPERTIES OF NiFeCr DEPOSITS }\end{array}$} \\
\hline $\begin{array}{l}\text { Bath temperature } \\
\left({ }^{\circ} \mathrm{C}\right)\end{array}$ & $\begin{array}{l}\text { Coercivity }\left(\mathrm{H}_{\mathrm{s}}\right) \\
(\mathrm{G})\end{array}$ & $\begin{array}{l}\text { Magnetization }\left(\mathrm{M}_{\mathrm{s}}\right) \\
\quad\left(\mathrm{emu} / \mathrm{cm}^{2}\right) 10^{-3}\end{array}$ & $\begin{array}{l}\text { Retentivity }\left(\mathrm{M}_{\mathrm{r}}\right) \\
\left(\mathrm{emu} / \mathrm{cm}^{2}\right) 10^{-3}\end{array}$ & $\begin{array}{l}\text { Squareness }(S) \\
\left(M_{\mathrm{r}} / \mathrm{m}_{\mathrm{s}}\right)\end{array}$ \\
\hline 30 & 364 & 93.72 & 37.27 & 0.3976 \\
\hline 50 & 245 & 125.83 & 42.51 & 0.3378 \\
\hline 70 & 209 & 146.73 & 44.40 & 0.3025 \\
\hline 90 & 132 & 222.15 & 51.03 & 0.2297 \\
\hline
\end{tabular}

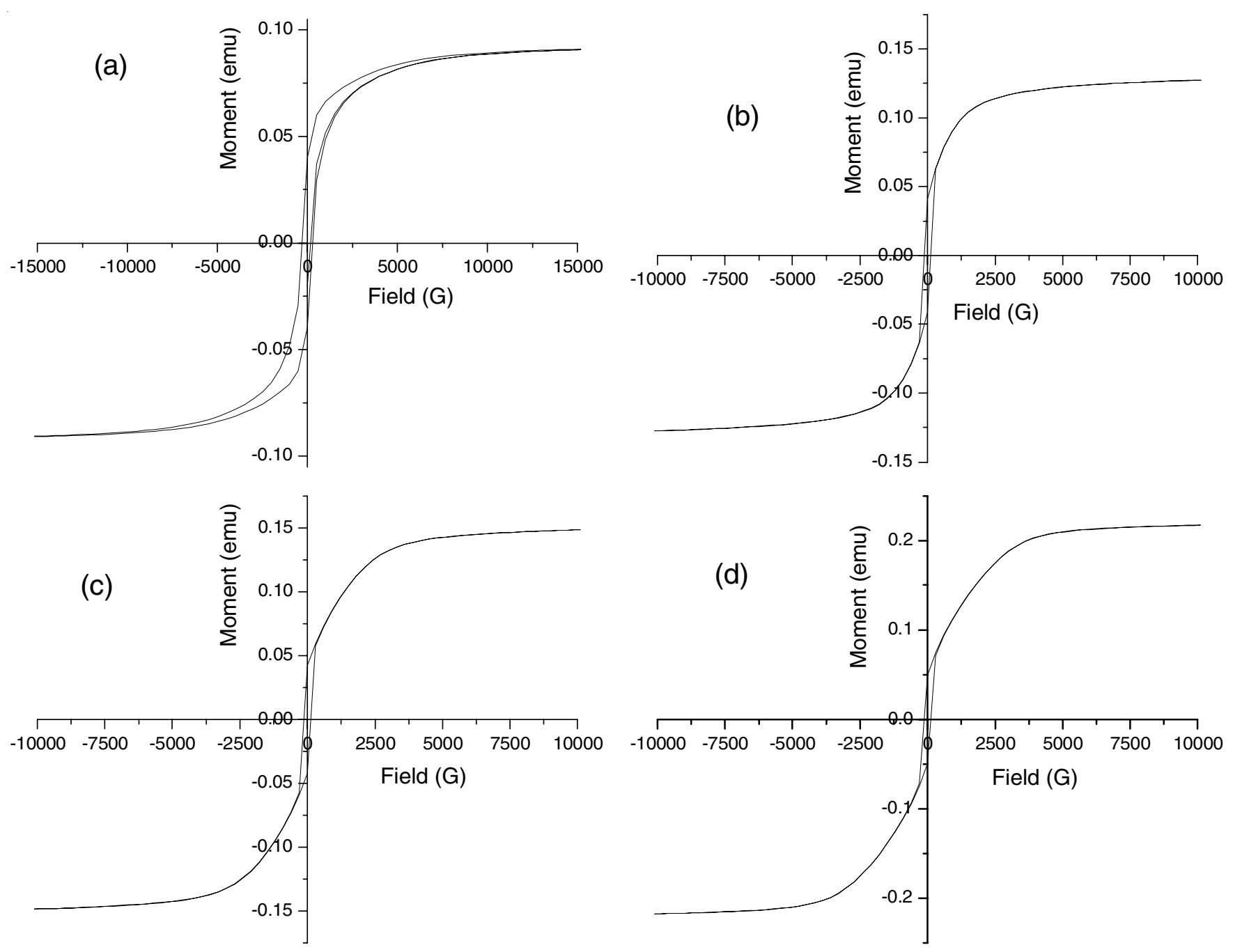

Fig. 5. Hysteresis curves for NiFeCr film at electrolytic bath temperatures (a) $30{ }^{\circ} \mathrm{C}$ (b) $50{ }^{\circ} \mathrm{C}$ (c) $70{ }^{\circ} \mathrm{C}$ (d) $90{ }^{\circ} \mathrm{C}$ 
The magnetization and other important magnetic property i.e., coercivity can be changed by decreasing the grain size of deposits. The film stress is reduced by increasing bath temperature. The $\mathrm{NiFeCr}$ thin films prepared at $90{ }^{\circ} \mathrm{C}$ have lower coercivity and higher magnetization due to low stress formation during deposition. So it is concluded that soft magnetic nature of $\mathrm{NiFeCr}$ thin films are enhanced by increasing bath temperature.

\section{Conclusion}

The $\mathrm{NiFeCr}$ alloy thin films at different temperature were prepared by electrodeposition, maintaining current density 3 $\mathrm{mA} / \mathrm{cm}^{2}$ and $\mathrm{pH}$ of solutions 6.0. The thin films are bright and uniformly coated on the surface. The XRD result reveal the existence of FCC type crystal. The crystalline size of deposits decreases due to online orientation of crystal while increasing bath temperature. The hardness increases with increasing bath temperature due to lower stress associated with thin films. When bath temperature is increased from 30 to $90{ }^{\circ} \mathrm{C}$, the magnetization increases from $93.72 \times 10^{-3}$ to $222.15 \times 10^{-3}$ $\mathrm{emu} / \mathrm{cm}^{2}$. Also when temperature is increased from 30 to 90 ${ }^{\circ} \mathrm{C}$, the coercivity decreases from $364 \mathrm{G}$ to $132 \mathrm{G}$. This is due to nanocrystalline structure of deposits. The addition of chromium with $\mathrm{NiFe}$ alloy in electroplating can enhance its magnetic, mechanical and structural properties and this alloy films can be used in NEMS, MEMS and memory devices.

\section{REFERENCES}

1. N.V. Myung, D.Y. Park, B.Y. Yoo and P.T.A. Sumodjo, J. Magn. Magn. Mater, 265, 189 (2003); https://doi.org/10.1016/S0304-8853(03)00264-6.

2. G.A. Di Bari, Modern Electroplating, John Wiley \& Sons, Inc., edn 5, p. 79 (2000).

3. K.Y. Kok, C.M. Hangarter, B. Goldsmith, I.K. Ng, N.B. Saidin and N.V. Myung, J. Magn. Magn. Mater, 322, 3876 (2010); https://doi.org/10.1016/j.jmmm.2010.08.012.
4. G.V. Fernandez, P.J. Grundy and M.M. Vopson, J. Phys. Condens. Matter, 1, 6 (2013); https://doi.org/10.12966/jcmp.08.02.2013.

5. M. Bedir, O.F. Bakkaloglu, I.H. Karahan and M. Oztas, Pramana, 66, 1093 (2006); https://doi.org/10.1007/BF02708462.

6. N. Myung, Bull. Korean Chem. Soc., 22, 994 (2001).

7. J. Singh, S.K. Gupta, A.K. Singh, P. Kothari, R.K. Kotnala and J. Akhtar, J. Magn. Magn. Mater, 324, 999 (2012); https://doi.org/10.1016/j.jmmm.2011.10.009.

8. S. Esmaili, M.E. Bahrololoom and C. Zamani, Surf. Eng. Appl. Electrochem., 47, 107 (2011); https://doi.org/10.3103/S1068375511020049.

9. R. Kannan, S. Ganesan and T.M. Selvakumari, Dig. J. Nanomater. Biostruct., 7, 1039 (2012).

10. G. Dixit, J.P. Singh, R.C. Srivastava, H.M. Agrawal, R.J. Choudhary and G. Ajay, J. Indian Pure Appl. Phys., 48, 287 (2010).

11. N. Gupta, A. Verma, S.C. Kashyap and D.C. Dube, Solid State Commun., 134, 689 (2005); https://doi.org/10.1016/j.ssc.2005.02.037.

12. N. Sulztanu and J. Fbrinza, J. Optoelectron. Adv. Mater, 6, 641 (2004).

13. Chih-Huang Lai, H. Matsuyama, R.L. White and T.C. Anthony, IEEE Trans. Magn., 31, 2609 (1995); https://doi.org/10.1109/20.490068.

14. R.N. Emerson, C.J. Kennady and S. Ganesan, Thin Solid Films, 515, 3391 (2007); https://doi.org/10.1016/j.tsf.2006.09.034.

15. M. Ghorbani, A.G. Dolati and A. Afshar, Russ. J. Electrochem., 38, 1173 (2002); https://doi.org/10.1023/A:1021141524584.

16. Y. Motomura, T. Tatsumi, H. Urai and M. Aoyama, IEEE Trans. Magn., 26, 2327 (1990); https://doi.org/10.1109/20.104714.

17. R. Kannan, S. Ganesan and T.M. Selvakumari, Optoelectr. Adv. Mater. Rapid Commun., 6, 383 (2012).

18. X.F. Meng, D.H. Li, X.Q. Shen and W. Liu, Appl. Surf. Sci., 256, 3753 (2010); https://doi.org/10.1016/j.apsusc.2010.01.019.

19. P. Esther and C. Joseph Kennady, J. Non Oxide Glasses, 1, 35 (2010).

20. Z. Abdel Hamid, Mater. Lett., 57, 2558 (2003); https://doi.org/10.1016/S0167-577X(02)01311-3. 